\title{
PUBLICATIONS COMMITTEE
}

Professor E. H. S. Simmonds, M.A. (Chairman).

Professor K. A. Ballhatchet, M.A., Ph.D.

Professor C. F. Beckingham, M.A.

A. D. H. Bivar, M.A., D.Phil.

S. E. Digby, M.A.

A. K. Irvine, M.A., D.Phil. (Editor).

A. V. Kunst, M.A., D.Phil. (Review Editor).

Susan A. Skilliter, M.A., Ph.D.

E. P. Southall. 